\title{
Terapêutica cirúrgica da hiperplasia fibrosa inflamatória gengival
}

\section{Surgical therapy of inflammatory fibrous hyperplasia of the gingiva}

Joseane Mary de Queiroz Nascimento ${ }^{1}$, Monyk dos Santos Braga ${ }^{1}$, Sidinéia Feitoza de Jesus ${ }^{1,2}$, Eric Barbosa de Camargo ${ }^{1,2}$, José Maurício de Souza Cruz Veloso Filho ${ }^{1,2}$, Elizangela Patata Zuza ${ }^{1}$, Juliana Rico Pires ${ }^{1}$

${ }^{1}$ Programa de Pós-graduação em Ciências Odontológicas, Centro Universitário da Fundação Educacional de Barretos (UNIFEB) - Barretos (SP), Brasil.

${ }^{2}$ Instituto Amazônia de Ensino Superior (IAES) - Manaus (AM), Brasil.

\section{Resumo}

A hiperplasia fibrosa inflamatória (HFI) gengival é uma lesão caracterizada por crescimento tecidual, também considerada uma lesão reacional que se forma como resposta a um irritante crônico local. O propósito do presente trabalho é relatar o caso de um paciente portador de aparelho ortodôntico fixo que apresentou hiperplasia gengival, mostrando seu diagnóstico e tratamento. Ele fazia uso de aparelho ortodôntico havia mais de dois anos e procurou tratamento queixando-se de alterações na gengiva. A hiperplasia estava presente nos incisivos centrais inferiores, com ausência de bolsa periodontal e de perda óssea vertical. Propuseram-se gengivoplastia e gengivectomia da região e instruiu-se higiene bucal. O exame histopatológico revelou a presença de hiperplasia gengival inflamatória não neoplásica. Concluiu-se que a progressão da HFI gengival pode ser facilmente influenciada pelo biofilme bacteriano. Dessa forma, a escolha do tratamento deve envolver, além de remoção cirúrgica, adequada instrução de higiene bucal, a fim de prevenir a recidiva da lesão.

Palavras-chave: hiperplasia gengival; gengivoplastia; terapêutica.

\begin{abstract}
Fibrous inflammatory gingival hyperplasia is a lesion characterized by tissue growth and is also considered a reactive lesion formed in response to a chronic local irritant factor. The purpose of this study is to report the case of a patient who uses fixed orthodontic appliance and presented gingival hyperplasia, showing the diagnosis and the treatment. The patient had been using orthodontic appliance for more than 2 years and sought treatment with the complaint of gingival changes. Hyperplasia was present in the lower central incisors, without periodontal pocket and vertical bone loss. Gingivoplasty and gingivectomy in the area was proposed and oral hygiene instruction was given. The histopathological exam revealed the presence of an inflammatory non-neoplastic hyperplasia of the gingiva. The progression of fibrous inflammatory gingival hyperplasia can be easily influenced by bacterial biofilm, and, therefore, the choice of treatment should involve adequate oral hygiene instruction in addition to surgical removal of tissue, in order to prevent recurrence of lesions.
\end{abstract}

Keywords: gingival hyperplasia; gingivoplasty; therapeutics.

Autor para correspondência: Joseane Mary de Queiroz Nascimento - Rua Prof. Roberto Frade Monte, 389 - Bairro Aeroporto - CEP: 14783-226 - Barretos (SP), Brasil - E-mail: joseane.mqnascimento@gmail.com Recebido em: 09 de abril de 2015 Aceito para publicação em: 21 de abril de 2016 


\section{Introdução}

A hiperplasia gengival é um aumento de volume do tecido gengival que prejudica a saúde periodontal, podendo ser induzida por biofilme ou resultar de inflamação associada a problemas sistêmicos ou irritantes locais, em decorrência de aparelhos ortodônticos (JORDÃO et al., 2007).

As hiperplasias se classificam com base no tecido que as forma, podendo ser com predomínio de tecidos de granulação (granuloma piogênico), fibroso (HFI) ou classificadas como outras lesões hiperplásicas (hiperplasia gengival induzida por fármacos) (ESPINOZA et al., 2006).

Nas primeiras etapas do desenvolvimento da lesão, o fator irritante crônico estimula a formação de um tecido de granulação, que começa a sofrer, posteriormente, o processo de fibrose. A presença de fatores irritantes na mucosa desencadeia um processo inflamatório crônico que culmina na formação de tecido fibroso hiperplásico, assintomático, nas áreas agredidas, conhecido como HFI (MACEDO et al., 2005). Tal hiperplasia é considerada um aumento celular proliferativo não neoplásico que se desenvolve na presença de fatores irritativos crônicos de baixa intensidade (PEDRON et al., 2009).

Sua etiologia é variada, podendo estar associados fatores irritantes, como biofilme, cálculo, aparelho ortodôntico, prótese mal-adaptada, má-oclusão e desequilíbrios hormonais (SAPP et al., 2004).

Na clínica odontológica, as HFIs são facilmente diagnosticadas pelo crescimento tecidual exofítico, séssil ou pediculado, de coloração rósea a eritematosa (RAMIREZ et al., 2002). O padrão histológico da hiperplasia gengival inflamatória caracteriza-se por epitélio pavimentoso estratificado paraqueratinizado, que emite longas e finas projeções em direção à lâmina própria, que é formada por tecido conjuntivo denso, bem celularizado e colagenizado, apresentando infiltrado inflamatório crônico composto de leucócitos polimorfonucleares (BARACK et al., 1985).

Ocorre com mais frequência na segunda década de vida, com mais prevalência no gênero feminino, possivelmente por causa de efeitos vasculares hormonais (JAFARZADEH et al., 2006). As lesões de natureza inflamatória constituem aproximadamente $66 \%$ de todas as lesões da cavidade oral, sendo, em sua maioria, atribuídas à má higiene bucal. Em adultos, está principalmente associada ao uso de próteses mal-adaptadas, enquanto em crianças e adolescentes está mais associada à presença de biofilme (RODRIGUEZ e SACSAQUISPE, 2005).

O tratamento de primeira escolha normalmente é a excisão cirúrgica, associada à remoção dos fatores locais (SILVA-SOUZA et al., 2000).

A gengivectomia está bem indicada para remoção das hiperplasias gengivais e, na maioria dos casos, as técnicas de gengivoplastia e gengivectomia são utilizadas em associação para remodelação gengival (BINNIE, 2000; CAMPOS et al., 2000; ROSSETTI et al., 2006). As cirurgias plásticas periodontais restituem a forma e a função do tecido gengival aumentado, contribuindo para uma melhora estética e funcional (MACIEL e MARTINS, 2012).

A gengivectomia é um procedimento cirúrgico desenvolvido com o objetivo de eliminar bolsas periodontais supraósseas, pela excisão de tecidos moles (GOLDMAN, 1951). Contudo, atualmente, sua indicação resume-se ao tratamento de hiperplasias gengivais (FARIA, 2007).

A gengivoplastia é a remodelação do tecido gengival, porém não tem o intuito de eliminar bolsas periodontais, mas sim restabelecer a forma anatômica e um contorno fisiológico adequado, visando à estética (AAP, 2001).

O propósito do presente trabalho foi apresentar o diagnóstico e o tratamento de um caso clínico de HFI gengival.

\section{Relato de Caso}

Paciente do gênero masculino, com melanoderma, 22 anos de idade, natural de Manaus (AM), fazendo uso de aparelho ortodôntico há mais de dois anos, procurou tratamento odontológico queixando-se de alterações na gengiva.

Durante a anamnese, relatou que não fazia uso de medicamentos. Ao exame clínico, observou-se crescimento gengival entre os dentes 33 e $43 \mathrm{em}$ direção coronal, de coloração rósea, base séssil, superfície lisa, alcançando os braquetes do aparelho ortodôntico. No exame periodontal, verificou-se que não havia presença de bolsa periodontal, nem perda de inserção. Radiograficamente, não havia evidências de perda óssea vertical nem achados de lesões, porém todas as faces dos dentes envolvidos (33 a 43) apresentavam sangramento e acúmulo de biofilme dental. A hipótese clínica diagnóstica foi de hiperplasia gengival inflamatória (Figuras 1 e 2) e o tratamento cirúrgico foi realizado em associação com gengivectomia e gengivoplastia. 


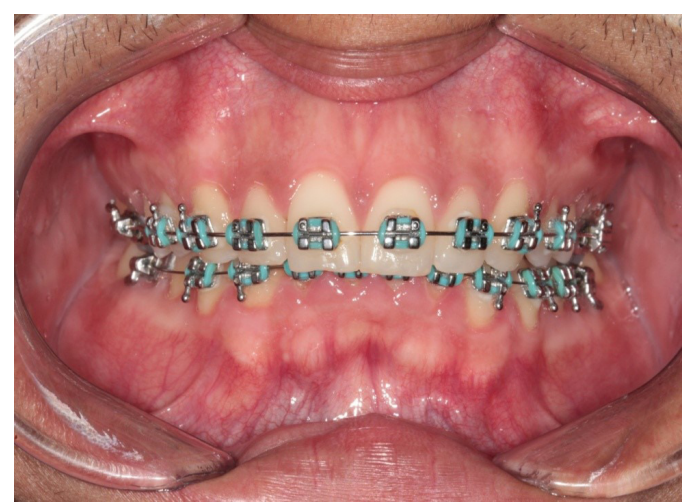

Figura 1. Exame inicial - Tecido gengival hiperplasiado (33 a 43).

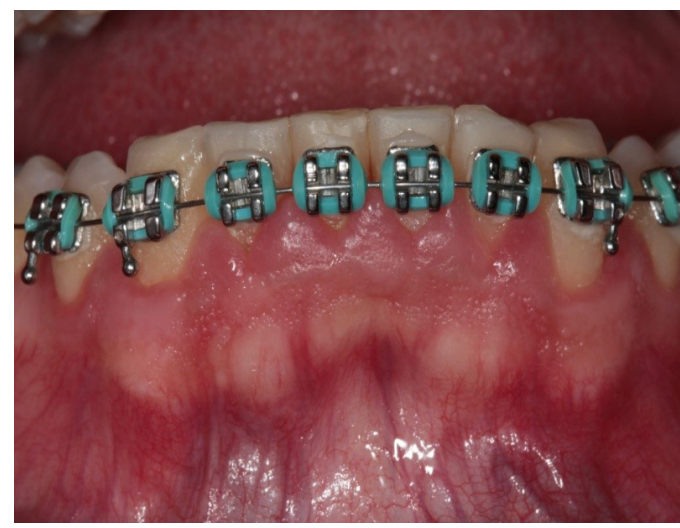

Figura 2. Tecido gengival apresentando crescimento coronal exacerbado e acúmulo de biofilme.

Antes da cirurgia, procedeu-se a raspagem e alisamento radicular de todos os dentes em sessão única e polimento coronário com taça de borracha (tratamento periodontal inicial), profilaxia dental e orientação de higiene adequada de todos os dentes.

$\mathrm{O}$ paciente foi submetido à anestesia local, mediante bloqueio bilateral dos nervos mentuais e incisivos e, depois, à sondagem com sonda periodontal milimetrada para mensurar a quantidade de tecido a ser removido a partir da distal do elemento 33 até a distal do elemento 43.

Realizaram-se anestesia bilateral do nervo mentoniano e anestesia infiltrativa para complemento e melhor conforto ao paciente. Com o auxílio da pinça Crane Kaplan, efetuaram-se a marcação dos pontos a serem incisionados (fundo de sulco ou bolsa periodontal) (Figura 3) e a incisão em bisel externo com bisturi de Kirkland, unindo-se

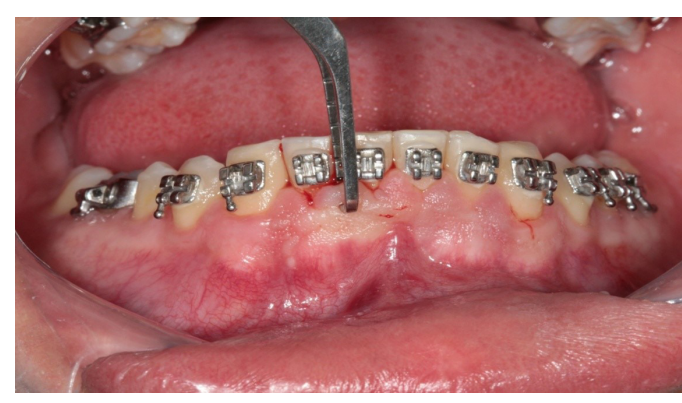

Figura 3. Marcação da profundidade de sulco para remoção de tecido.

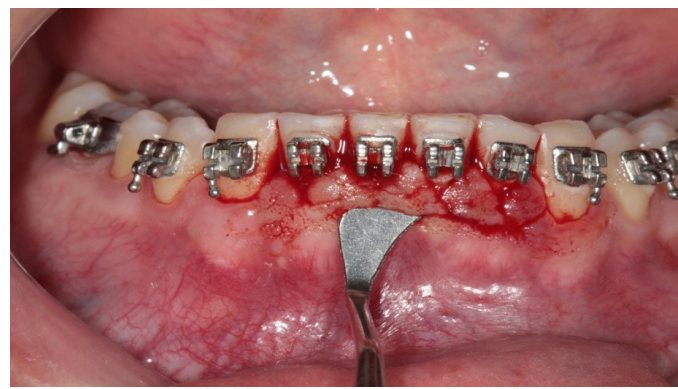

Figura 4. Incisão inicial em bisel externo com bisturi de Kirkland (união dos pontos demarcados).

os pontos demarcados, liberando, posteriormente, os tecidos proximais com o bisturi de Orban (Figuras 4 e 5). Removeu-se o tecido incisionado com cureta periodontal, sendo este acondicionado em recipiente adequado para análise histopatológica (Figura 6).

A gengivoplastia foi executada com bisturi de Kirkland e alicate (tipo de cutícula) na interproximal dos dentes, seguida de raspagem e alisamento radicular dos elementos 33 ao 43 .

O material removido foi enviado para exame histopatológico. Nesse momento, com a remoção do tecido hiperplasiado, foi possível verificar a presença de excesso de material utilizado para colagem dos braquetes ortodônticos (resina), sendo esse material removido, deixando a superfície dental lisa e polida (Figuras 7-9).

Depois de irrigação abundante com solução estéril de cloreto de sódio a $0,9 \%$, o cimento cirúrgico foi aplicado na região e, com o auxílio dos braquetes, promoveu excelente fixação dele (Figura 10). No pós-operatório imediato, prescreveram-se analgésico (dipirona sódica) a cada seis horas nas primeiras 24 horas, em caso 


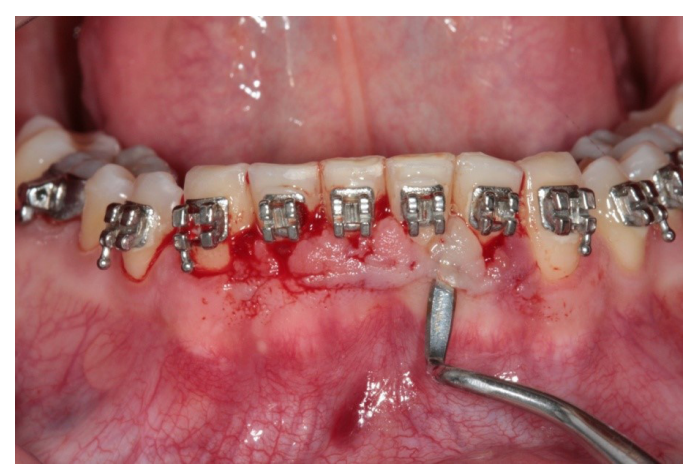

Figura 5. Liberação do tecido proximal com bisturi de Orban.

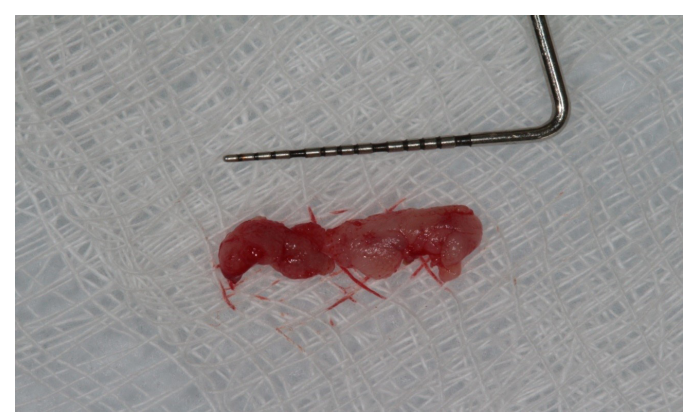

Figura 6. Peça cirúrgica removida.

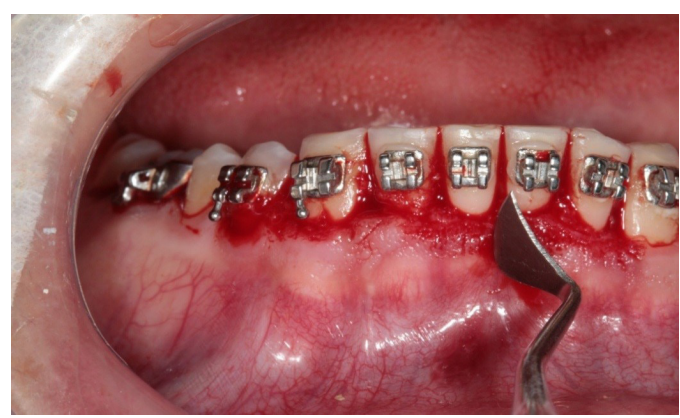

Figura 7. Gengivoplastia com bisturi de Kirkland.

de dor, e anti-inflamatório (nimesulida) a cada 12 horas, durante três dias.

O cimento cirúrgico foi removido no pós-operatório de sete dias (Figura 11), não tendo o paciente relatado dor. Clinicamente, o tecido apresentava-se com boa condição de reparo tecidual, sem sinais de infecção ou edema. Após 60 dias, observaram-se ausência de inflamação ou sintomatologia, restauração do contorno gengival

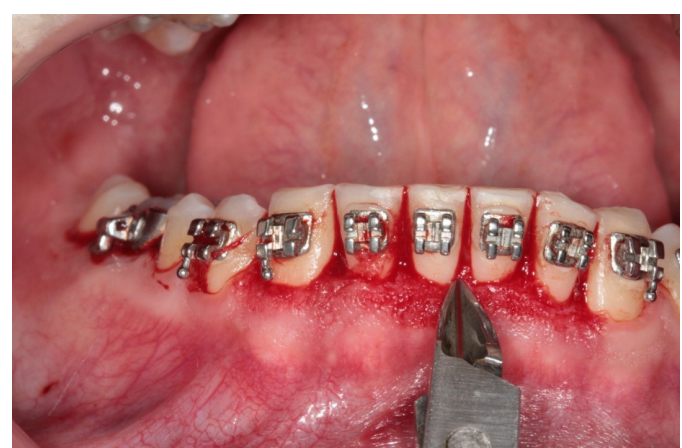

Figura 8. Gengivoplastia na área interproximal com alicate de cutícula.

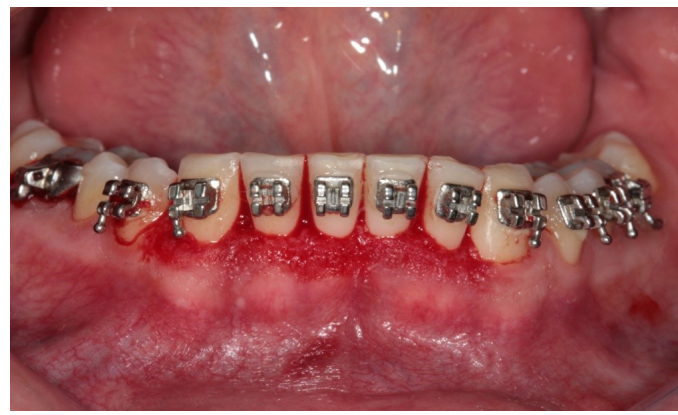

Figura 9. Aspecto da ferida cirúrgica no pós-operatório imediato.

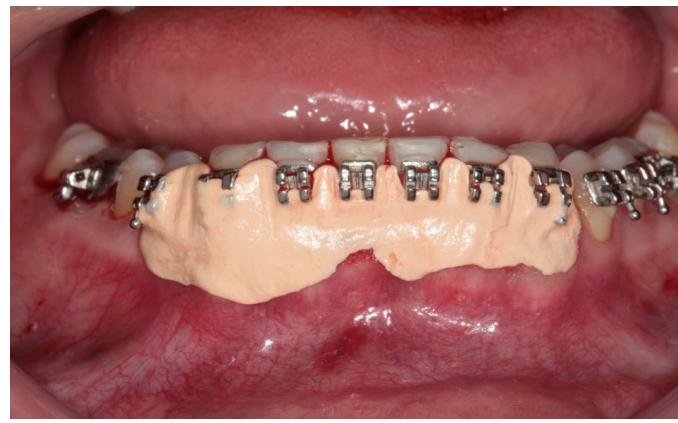

Figura 10. Colocação de cimento cirúrgico.

fisiológico e manutenção de faixa adequada de tecido queratinizado (Figura 12).

\section{Discussão}

Dentre os processos proliferativos gengivais não neoplásicos, os mais frequentes são hiperplasia gengival inflamatória e granuloma piogênico. Fibroma periférico, lesão periférica de células gigantes e hiperplasia gengival medicamentosa 


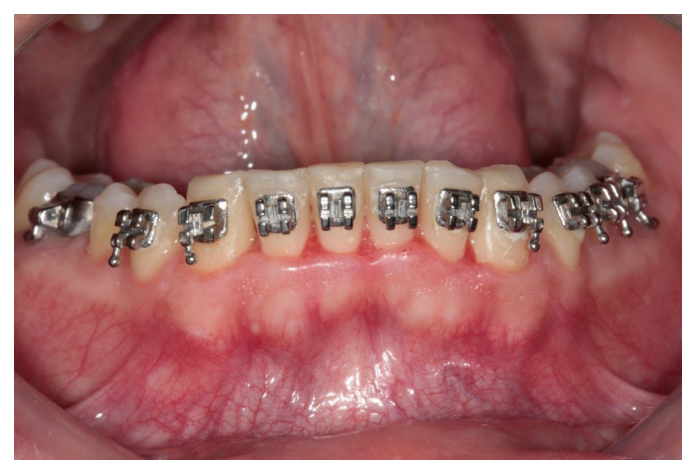

Figura 11. Área cirúrgica aos sete dias de pós-operatório.

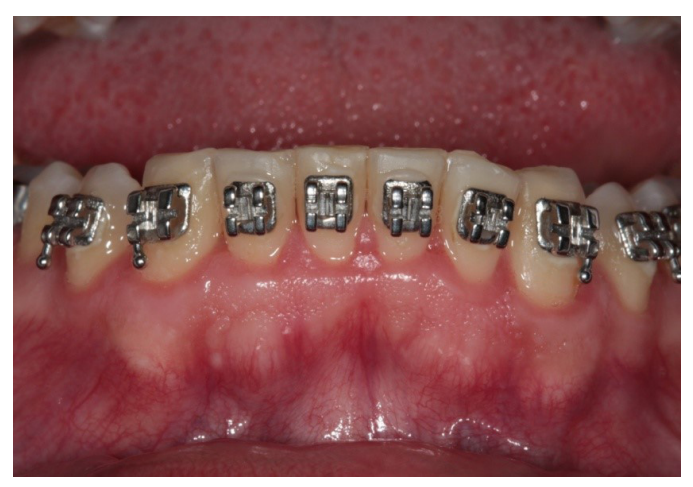

Figura 12. Área cirúrgica aos 60 dias de pósoperatório.

também compõem esse grupo, porém em menor incidência (COLEMAN et al., 2002).

A etiopatogenia da hiperplasia gengival possui diversas hipóteses, entre elas biofilme associado a fatores irritativos de baixa intensidade, como o uso de aparelhos ortodônticos e próteses mal adaptadas (PEDRON, 2002; SAKAKURA et al., 2004). Os componentes do aparelho ortodôntico podem levar ao acúmulo de biofilme dental, caso não haja correta higienização (RABELO et al., 2013). No caso relatado, o paciente fazia uso de aparelho ortodôntico, sendo um fator relevante para o desenvolvimento da doença.

O trauma durante a colocação do aparelho ortodôntico e a persistência desse trauma são capazes de promover áreas de espessamento do epitélio e proliferação do tecido conjuntivo, resultando em aumento tecidual. O processo alérgico desencadeado em resposta ao monômero da resina acrílica da base dos aparelhos removíveis, associado à presença fúngica (Candida albicans), também é considerado um fator etiológico (BARACK et al., 1985). No presente caso, após a remoção da gengiva hiperplásica, observou-se excesso de material resinoso, extravasado ao redor dos braquetes, sugerindo ser uma das possíveis causas da hiperplasia gengival, com o biofilme bacteriano.

Os processos proliferativos não neoplásicos caracterizam-se pelo crescimento de tecido gengival bem delimitado, como nódulos ou difusos, com massas teciduais de consistência fibrosa ou flácida, de sintomatologia e coloração variadas (de rósea a eritematosa), de base séssil a pediculada, normalmente apresentando sangramento ao toque, com perda do aspecto de casca de laranja na superfície (COLEMAN et al., 2002), características essas semelhantes às encontradas no caso clínico relatado.

Diversas lesões compõem o diagnóstico diferencial, como hemangiogranuloma, granuloma piogênico, lesão periférica de células gigantes (estágios iniciais), fibrogranuloma (estágios mais avançados) (COLEMAN et al., 2002). Pela amplitude do diagnóstico diferencial, sugeriu-se a realização de exame histológico para verificar e elucidar o diagnóstico de lesões gengivais (HALLIDAY et al., 2007).

O exame histopatológico demonstrou fragmento de mucosa revestida por epitélio pavimentoso estratificado, proliferação de tecido fibrovascular e infiltrado inflamatório perivascular leve constituído por linfócitos, histiócitos e plasmócitos. Como diagnóstico final, constatou-se HFI gengival, reafirmando o diagnóstico clínico inicial de hiperplasia gengival inflamatória relacionada aos fatores irritantes locais, que seriam o aparelho ortodôntico e a placa bacteriana.

Nesse tipo de lesão hiperplásica, são necessárias a remoção dos fatores causais, por meio de tratamento periodontal básico (sessões de raspagem e alisamento radicular, polimento coronorradicular), e a instrução de higiene oral (SAKAKURA et al., 2004). A terapia periodontal básica é aplicada para diminuir o nível de microrganismos, otimizando a regressão da inflamação, mas nem sempre reestabelece o contorno gengival original, havendo, assim, a necessidade de procedimento cirúrgico para correção (AAP, 2001). Dessa forma, é imprescindível realizar tratamento periodontal básico antes da cirurgia, para restabelecer a saúde bucal. 
O tratamento para as lesões não neoplásicas é a excisão cirúrgica (SHENOY e DINKAR, 2006). Porém, algumas complementações devem ser utilizadas, como a curetagem (BARACK et al., 1985), a gengivectomia e/ou a gengivoplastia (BINNIE, 2000). Nesse caso clínico, o tratamento de escolha foi gengivectomia associada à gengivoplastia, em razão de a hiperplasia estar localizada em área estética, sendo complementada com raspagem e alisamento radicular.

A gengivoplastia é similar à gengivectomia, porém seu objetivo é diferente: a gengivectomia é realizada para eliminar a bolsa periodontal, realizando-se, durante essa técnica, o recontorno da gengiva. A gengivoplastia é o recontorno da gengiva, devolvendo os contornos gengivais fisiológicos. Essa técnica consiste em criar um contorno marginal escalopado, afilar a margem gengival, diminuir a gengiva inserida, criando sulcos verticais interdentários, e modelar as papilas interdentais (CARRANZA et al., 2012).

A gengivectomia apresenta como maiores vantagens a simplicidade e a facilidade de realização, sendo, em geral, realizada ao mesmo tempo que a gengivoplastia. Ambas as técnicas apresentam como vantagens a previsibilidade e a simplicidade (COHEN, 2008).

Pacientes em tratamento ortodôntico devem utilizar componentes ortodônticos que não ofereçam riscos ao periodonto. Alterações periodontais devem ser precocemente diagnosticadas e tratadas, tornando-se importantes controle por meio de tratamento periodontal básico e reforço da higiene bucal (SAKAKURA et al., 2004). Nos casos de recorrência, esta está usualmente relacionada à não remoção dos fatores irritativos locais e à remoção parcial da lesão (RIVERO e ARAÚJO, 1998), sendo calculada, nesses casos, em torno de $14 \%$ a $16 \%$ (GRAHAM, 1996).

A HFI gengival é um processo proliferativo não neoplásico, associado a trauma crônico de baixa intensidade, sendo sua progressão facilmente influenciada pelo biofilme. Para não haver recidiva da lesão e para ocorrer um bom prognóstico, associou-se a excisão cirúrgica da lesão à remoção dos fatores irritantes locais.

\section{Conclusão}

O exame histopatológico é conclusivo para elucidar o diagnóstico das lesões gengivais, confirmando o diagnóstico de HFI gengival. Os tratamentos de escolha para esse caso de hiperplasia foram adequado tratamento periodontal não cirúrgico e controle de placa, associados à exérese da lesão, apresentando, dessa forma, bom prognóstico clínico e preservação do caso a longo prazo.

\section{Referências}

AMERICAN ACADEMY OF PERIODONTOLOGY - AAP. Glossary of periodontal terms. $4^{\text {th }}$ ed. Chicago: American Academy of Periodontology, 2001.

BARACK, D.; STAFFILENO, H.; SADOWSKY, C. Periodontal complication during orthodontic therapy. American Journal of Orthodontics, v. 88, n. 6, p. 461-465, 1985.

BINNIE, W.H. Periodontal cystis and epulides. Periodontol, v. 21, p. 16-32, 2000.

CAMPOS, V.; BITTENCOURT, L.P.; MAIA, L.C.; ANDRADE, M.; MASCARENHAS, A. Granuloma piogênico: descrição de dois casos clínicos. Jornal Brasileiro de Odontopediatria e Odontologia do Bebe, v. 3, n. 12, p. 170-175, 2000.

CARRANZA, F.A.; NEWMAN, M.G.; TAKEI, H.H.; KLOKKEVOLD, P.R. Periodontia clínica. 11. ed. Rio de Janeiro: Editora Elsevier, 2012. p. 685-688.

COHEN, E.S. Atlas de cirurgia periodontal reconstrutiva e cosmética. 3. ed. São Paulo: Editora Santos, 2008. p. 38-44.

COLEMAN, G.C.; FLAITZ, C.M.; VINCENT, S.D. Differential diagnosis of oral soft tissue lesions. Texas Dental Journal, v. 119, n. 6, p. 484-503, 2002.

ESPINOZA, Z.M.; LOZA, H.G.; MONDRAGÓN, B.R. Prevalencia de lesiones de La mucosa bucal em paciente pediátricos: informe preliminar. Cirugia y Cirujanos, v. 74, p. 153-157, 2006.

FARIA, A.R. Cirurgia estética periodontal. 1. ed. Porto: Editora Facies, 2007. p. 38-52.

GOLDMAN, H. Gingivectomy. Oral Surgery, Oral Medicine, Oral Pathology, Oral Radiology, v. 4, n. 9, p. 1136-1157, 1951. 
GRAHAM, R.M. Pyogenic granuloma: an unusual presentation. Dental Update, v. 23, n. 6, p. 240241, 1996.

HALLIDAY, H.; GORDON, S.; BHOLA, M. Case report: an unusually large epulis on the maxillary gingiva of a 24-year-old woman. General Dentistry, v. 55, n. 3, p. 232-235, 2007.

JAFARZADEH, H.; SANATKHANI, M.; MOHTASHAM, N. Oral pyogenic granuloma: a review. Journal of Oral Science, v. 48, n. 4, p. 167-175, 2006.

JORDÃO, K.C.F.; SPIN NETO, R.; MARCANTONIO JUNIOR, E. Aumento de coroa clínica com finalidade estética e funcional: relato de caso clínico. Revista de Odontologia da UNESP, v. 36, n. esp. p. 1, 2007.

MACEDO, L.F.; DIAS, J.A.; ANTONIO, L.G. Study of denture induced fibrous hyperplasia cases diagnosis from. Quintessence International, v. 36, n. 10 , p. $825-829,2005$.

MACIEL, T.N.; MARTINS, F.R. Aumento de coroa clínica estético. Revista Uniplac, v. 1, n. 1, 2012.

PEDRON, I.G. Interação entre as especialidades odontológicas: Ortodontia e Periodontia. Sobrape, v. 1, n. 7, 2002.

PEDRON, I.G.; GOMES, T.; LOUREIRO, C.C.S.; ABURAD, A.; ADDE, C.A. A doença periodontal como fato etiopatogênico à hiperplasia gengival inflamatória. La Revue Odontologique, v. 17, n. 34, p. 76-81, 2009.

RABELO, A.C.N.; ROSA, T.S.; GOMES, C.S.B. Hiperplasia gengival em usuários de aparelho ortodôntico fixo. Caderno de Ciências Biológicas e da Saúde, v. 1, 2013.
RAMIREZ, K.; BRUCE, G.; CARPENTER, W. Pyogenic granuloma: case report. General Dentistry, v. 50, n. 3, p. 280-281, 2002.

RIVERO, E.L.C.; ARAÚJO, L.M.A. Granuloma Piogênico: uma análise clínico-histopatológica de 147 casos bucais. Revista da Faculdade de Odontologia-UPF, v. 3, n. 2, 1998.

RODRIGUEZ, A.F.; SACSAQUISPE, S.J. Hyperplasia Fibrosa Inflamatória y posibles factores asociados em adultos mayores. Revista Estomatológica Herediana, v. 15, n. 2, p. 139144, 2005.

ROSSETTI, E.P.; SAMPAIO, L.M.; ZUZA, E.P. Correção de assimetria dentogengival com finalidade estética: relato de caso clinico. Revista Gaúcha de Odontologia, v. 54, p. 384-387, 2006.

SAKAKURA, C.E.; RIBEIRO, F.S.; QUEIROZ, T.P.; CIRELLI, J.A. Influência do tratamento ortodôntico sobre a condição periodontal: um caso clínico. Jornal Brasileiro de Ortodontia e Ortopedia Facial., v. 9, n. 53, p. 435-439, 2004.

SAPP, J.P.; EVERSOLE, L.R.; WYSOCKI, S.P. Patologia oral y maxilofacial contemporânea. 2. ed. Mosby: Elsevier, 2004. p. 336-337.

SHENOY, S.S.; DINKAR, A.D. Pyogenic granuloma associated with bone lass in an eight year old child: a case report. Journal of the Indian Society of Pedodontics and Preventive Dentistry, v. 24, n. 4, p. 201-203, 2006.

SILVA-SOUZA, Y.T.; COELHO, C.M.; BRENTEGANI, L.G.; VIEIRA, M.L.; OLIVERIA, M.L. Clinical and histological evalution of granuloma gravidarum: case report. Brazilian Dental Journal, v. 11, n. 2, p. 135-139, 2000. 